\title{
The Emerging Potentials of Human Regulatory B Cells Mediated Therapies in Myasthenia Gravis.
}

\author{
Md Rezaul Karim ${ }^{1 *}$ \\ ${ }^{1}$ Institute of Neuroscience, Hubei University of Medicine, Shiyan, China \\ *Correspondence address: Institute of Neuroscience, Hubei University of Medicine, 30 South \\ Renmin Road, Shiyan, Hubei 442000, China; Email: dr_mdrezaulkarim@hotmail.com
}

\begin{abstract}
Regulatory B cells (Bregs) with immunosuppressive function are critical in maintaining immune tolerance. In recent years, Bregs is an essential part of the study due to its therapeutic relevance and function in immune tolerance. The positive and negative regulatory role of human Bregs in immune tolerance is being discussed in several pathologies, including in autoimmune diseases, cancers, chronic infections, strokes in multiple reports. The negative regulatory roles of human Bregs are associated with lesser numbers and functional abnormalities in most of these studies, including myasthenia gravis (MG). In this review, the potential findings regarding human Bregs in $\mathrm{MG}$, and Bregs mediated potential therapeutic strategies with its pros and cons have been discussed based on previous and current reports.
\end{abstract}

Keywords: Human Bregs; IL-10; IL-35; TGF- $\beta$; myasthenia gravis; Bregs expansion

\section{INTRODUCTION}

Regulatory B cells, a subset of B cells that predominantly responsible for regulating the immune responses ${ }^{[1]}$. In addition to their crucial function antigen-presenting and antibody production, B cells can regulate immune responses through the secretion of cytokines. In autoimmune diseases, severe infections, tumors, and transplantation immune conditions activate the body's own immune system, thereby enabling the humoral immune regulatory system resulting in the activation of regulatory B cells, secreting anti-inflammatory cytokines, e.g., interleukin (IL)-10, transforming growth factor (TGF)- $\beta$. In healthy individuals, they maintain dynamic homeostasis at a certain level. In the disease state, the body's immune system is destroyed, causing their dynamic homeostasis to be broken, thus playing a role. As of the current state of knowledge, three cytokines have identified that are produced by Bregs, among which IL-10 considered the hallmark cytokine of Breg cells ${ }^{[2-5]}$. However, TGF- $\beta$ and IL-35 have also associated with B cell-mediated immunosuppression. 
TGF- $\beta$ is a pleiotropic cytokine that plays a role in a wide range of processes as well as immune regulation ${ }^{[6]}$, whereas IL-35 plays a role in immunosuppression through induction of Treg cell proliferation while suppressing $\mathrm{T}_{\mathrm{H}} 17$ responses. IL-35 primarily produced by Treg cells ${ }^{[7]}$. The importance of human Bregs in the maintenance of immune homeostasis comes from various immune-related pathologies such as cancers, and chronic infections, autoimmune diseases, including myasthenia gravis, which are often associated with abnormalities in Breg numbers or function ${ }^{[8]}$. Through the understanding of the regulatory role of human Bregs in myasthenia gravis, being able to identify the defect in numbers and function, and initiation of in vitro and in vivo therapeutic interventions targeting Bregs can anticipate a useful therapeutic method for MG. In this review, an overall discussion has been made based on previous and current reports on human Bregs in $\mathrm{MG}$ and their potential therapeutic strategies with all its positive and negative impacts.

\section{OVERVIEWS OF MG AND BREGS}

\subsection{An overview of myasthenia gravis}

Myasthenia gravis (MG) was first discovered as a distinct clinical entity by $\mathrm{T}$. Willis in his account in Latin in $1672{ }^{[9]}$. However, MG was not recognized until S. Wilks gave the first modern description in $1877^{[10]}$, where he described bulbar and peripheral muscular weakness and was struck by the absence of pathology in the central nervous system (CNS). The first full descriptions of MG were described by W. Erb in 1879 and afterward described by W. Goldflam in $1893^{[11-12]}$. The first description of a myasthenic patient with a thymic mass was made by C. Weigert in $1901^{[13]}$. The remarkable discovery of symptomatic treatment of MG was made by M. B. Walker in $1934^{[14]}$. J. A. Simpson made the first suggestion that MG is an autoimmune disease in $1960^{[15]}$, and the role of an autoimmune genesis of MG was confirmed as well as established a classification by K. E. Osserman and G. Genkins in $1971^{[16]}$ (see Figure 1). Further investigations of MG were done and are being conducted by multiple investigators.

\subsection{An overview of regulatory $B$ cells}

The idea of regulatory B cells (Bregs) first came into attention during delayed-type hypersensitivity (DTH) responses in guinea pigs in $1974^{[17-18]}$. It took more than 20 years until it came into the researcher's re-attention. In 1996, in a murine autoimmune model of experimental autoimmune encephalitis (EAE), it was noticed that the absence of B cells aggravated the inflammation ${ }^{[19]}$. In 1997, in chronic colitis, it was observed that the disease worsened in the B-cells deficient group ${ }^{[20]}$. In 2000, its suppressive ability in inflammatory 
bowel disease was observed and described using the term "regulatory B cell" [21]. In 2002, this subset of B cells was described again as IL-10-producing B cell ${ }^{[2]}$ due to its IL-10 expressibility (see Figure 2). Afterward, many studies have described the role of Bregs in various disease or conditions in both mice ${ }^{[22-28]}$ and humans ${ }^{[29-34]}$, more studies are required for phenotypic identification and characterization in human Bregs. Phenotypic identification of mice Bregs has been well established ${ }^{[3,30]}$, and human Bregs phenotypic identifications are now defined in studies as well ${ }^{[2,30,32-33,35]}$.

\subsection{Regulatory role of human Bregs in MG}

Myasthenia gravis is an autoimmune disease caused by a defect of nerve impulses transmission to muscles at the postsynaptic neuromuscular junction (NMJ). Around $85 \%$ of patients with MG possess anti-AChR antibodies that block acetylcholine receptors (AChRs) at NMJ, and $38-47 \%$ of patients with MG possess muscle-specific kinase (MuSK) autoantibodies ${ }^{[36-39]}$. B cells produce anti-AChR or MuSK autoantibodies with the aid of $\mathrm{T}$ cells and other lymphocytes, thus playing a negative role in MG pathophysiology ${ }^{[39]}$. B-cell subsets, called regulatory B cells, possess immunosuppressive functions that are linked to anti-inflammatory cytokines production and disease progression in $\mathrm{MG}$ patients. Studies have found the inverse correlations between abnormalities in human Bregs number and function with disease progression in patients with MG in vitro ${ }^{[33,40-43]}$.

\section{THERAPEUTIC POTENTIAL OF BREGS IN MG}

Most of the available treatments for various immune-related pathologies, including myasthenia gravis are symptomatic. Long-term therapies using these available medications may have a significant level of side effect, maybe ineffective or even may increase life-threatening infections. Thus, cell medicated therapy targeting specific immune cells that drive disease progression is becoming increasingly popular and proven effective in the treatment of cancers $[8,44]$. According to the current state of knowledge of the phenotypes and markers of human regulatory B cells, they produce IL-10, IL-35, and TGF- $\beta^{[33-34,45]}$. However, IL-10 is the only consensus marker for the majority of functional regulatory B cell subsets; therefore, regulatory B cells are well recognized as IL-10 producing B cells ${ }^{[2,46]}$. Multiple studies have shown a significant decrease in B10 cells in neuroimmunological disorders, including myasthenia gravis ${ }^{[33,41,47-49]}$. A study found that the treatment of experimental autoimmune myasthenia gravis (EAMG) mice with low-dose granulocyte-macrophage colony-stimulating factor (GM$\mathrm{CSF}$ ) increased the proportion of $\mathrm{CD} 1 \mathrm{~d}^{\text {hi }} \mathrm{CD}^{+} \mathrm{B}$ cells and $\mathrm{B} 10$ cells in vitro. 
In contrast, $\mathrm{CD} 1 \mathrm{~d}^{\text {hi }} \mathrm{CD}^{+} \mathrm{B}$ cells inhibited $\mathrm{B}$ cell proliferation and its autoantibody production in an IL-10-dependent manner. The study suggested that in vivo or in vitro expansion of $\mathrm{CD} 1 \mathrm{~d}^{\text {hi }} \mathrm{CD}^{+} \mathrm{B}$ cells or B10 cells may represent an effective strategy in the treatment of human myasthenia gravis ${ }^{[24]}$. Another study found that patients with MG had relatively lowered percentages of $\mathrm{CD} 19^{+} \mathrm{CD}^{+} \mathrm{CD} 1 \mathrm{~d}^{+}$Bregs as compared to healthy controls (HCs) and, the production of IL-10 and TGF- $\beta_{1}$ was relatively lesser in patients with MG than HCs, which were linked with more severe of MG disease status. The study suggested that MG Bregs could be cocultured in vitro with particular drug medium and in vitro research to develop B cellmediated therapies of $\mathrm{MG}^{[33]}$. Thus, in vitro expansion of Bregs; ex vivo expansion or, in vivo manipulation of Bregs; and depletion therapy of Bregs strategies would provide a new window of opportunity to treat MG (see Figure 3).

\subsection{In vitro expansion of Bregs}

Different combinations of stimuli have been used to quantify Bregs in various diseases ${ }^{[8]}$. IL10-producing B cells (Bregs) from patients with myasthenia gravis could be treated with certain medications such as steroids e.g., dexamethasone in vitro culture model. Bregs isolated from myasthenia gravis patient-derived peripheral drug mononuclear cells (PBMCs) using B cell isolation techniques and magnetic separation [34]. As the IL-10-producing B cells, $\mathrm{CD} 19^{+} \mathrm{CD}^{+} \mathrm{CD} 1 \mathrm{~d}^{+}$Bregs had been described to reduce in vitro in patients with myasthenia gravis, after in vitro treatment for a specific duration, in vitro expansion of $\mathrm{CD} 19^{+} \mathrm{CD}^{+} \mathrm{CD} 1 \mathrm{~d}^{+}$ Bregs to be observed using flow cytometry, and the induced IL-10 expression, which is the hallmark of regulatory B cells, can be observed using enzyme-linked immunosorbent assay (ELISA) or, cytometric bead array (CBA). The in vitro expansion of MG patient-derived $\mathrm{CD} 19^{+} \mathrm{CD}^{+} \mathrm{CD} 1 \mathrm{~d}^{+}$Bregs that are treated in the drug culture medium can be compared with MG patient-derived $\mathrm{CD} 19^{+} \mathrm{CD} 5^{+} \mathrm{CD} 1 \mathrm{~d}^{+}$Bregs that are drug-free medium.

\subsection{Ex vivo expansion or, in vivo manipulation of Bregs}

Studies suggest that the environmental milieu in which B cells differentiate plays a pivotal role in the induction of Bregs, and inflammatory cytokines such as Il-10 play a critical role in the induction of immunosuppressive Bregs. While several studies support the in vivo expansion of Bregs, they also suggest a potential risk of triggering undesirable pro-inflammatory responses [50-53]. Stimulation of IL-10-producing B cells (Bregs) isolated from myasthenia gravis patientderived PBMCs, followed by adoptive transfer of fluorescence-activated cell sorting (FACS)sorted Bregs, could reestablish tolerance. The expansion of Bregs by proinflammatory 
cytokines depends on the signals that they receive; thus, the accuracy concentration of the proinflammatory cytokine is crucial for the effector regulatory B cell expansion. Additionally, the identification of Breg differentiation-inducing stimuli provides new opportunities to induce a shift in B cells toward a more regulatory phenotype for the in vivo manipulation of Bregs ${ }^{[8]}$. A further observation can be made to find out whether modulating signals in vivo can provide a long-term favorable environment for Breg differentiation and whether it improves the function of MG disease status.

\subsection{Depletion therapy of Bregs}

Several studies found that the use of rituximab has shown some success in the treatment of autoimmune diseases ${ }^{[54]}$. Depleting of Bregs or effector B cell subsets would provide more advantages over currently used total B cell depletion therapies in the treatment of cancers and other immune disorders. Although there is a lack of surface markers specific for Bregs, several markers have been shown to identify the majority of IL-10-producing Bregs ${ }^{[2,29,55]}$. However, these are not precisely Breg-specific to use in cellular therapy ${ }^{[8]}$. Thus, further identification of Breg-specific markers could result in the development of depletion therapy of Bregs in patients with myasthenia gravis.

\section{POTENTIAL CHALLENGES}

Therapies targeted to modify Bregs exhibit great potential in myasthenia gravis treatment, but the identification of effective Breg subsets for cell-mediated therapy might be challenging. The current therapeutic approaches are based on in vivo immunosuppressive Bregs expansion or generation. Most of the studies on Breg generation were so far conducted in mice, among which one study reported that Bregs differentiate into antibody-secreting cells after transient IL-10 production in vivo ${ }^{[8,56]}$. Thus, without further detailed studies of human Bregs, it is rather difficult to carry out further cell-mediated therapies on human Bregs. On the other hand, an important consideration should be the quantity of Bregs, which are to be transferred for effective Bregs mediated therapy for myasthenia gravis. The main difficulties in the development of Bregs mediated therapy for myasthenia gravis is due to the unclear human Bregs definition and diversity of mechanism, as the current studies on human Bregs are a handful and less described ${ }^{[8,57]}$.

\section{CONCLUSION}


Available evidence indicates that therapeutic interventions targeting Bregs could provide improved approaches for the treatment of myasthenia gravis which can be in the following methods, such as method (1) Bregs phenotypic identification in isolated B cells from MG patient-derived PBMCs and in vitro expansion in drug medium and comparison with non-drug medium; method (2) Once ex vivo expansion of MG Bregs is completed then the adoptive transfer of these expanded cells into the patient could suppress autoimmunity in MG; in vivo modulation to expand Bregs in patients with MG to suppress autoimmunity or disease progress; method (3) in vivo depletion of Bregs as specific subsets of B cells would provide more advantages than current total B cell depletion therapies. Therefore, a constant attempt to understand Breg biology in healthy individuals versus MG can provide new possibilities to establish Breg immunotherapy in patients with MG.

\section{Disclosure of Conflicts of Interests}

None.

\section{Author Contributions}

MRK: concept development, review plan and performing review, manuscript writing and review of the manuscript.

\section{Acknowledgment}

Thanks to the Hubei University of Medicine, China for all the help.

\section{Funding}

Not applicable.

\section{REFERENCES}

1. Li, W., Tian, X., Lu, X., Peng, Q., Shu, X., Yang, H., ... Wang, G. (2016). Significant decrease in peripheral regulatory B cells is an immunopathogenic feature of dermatomyositis. Scientific Reports, 6(1). doi:10.1038/srep27479

2. Mizoguchi, A., Mizoguchi, E., Takedatsu, H., Blumberg, R. S., \& Bhan, A. K. (2002). Chronic Intestinal Inflammatory Condition Generates IL-10-Producing Regulatory B Cell Subset Characterized by CD1d Upregulation. Immunity, 16(2), 219-230. doi:10.1016/s1074-7613(02)00274-1 
3. Iwata, Y., Matsushita, T., Horikawa, M., DiLillo, D. J., Yanaba, K., Venturi, G. M., ... Tedder, T. F. (2010). Characterization of a rare IL-10-competent B-cell subset in humans that parallels mouse regulatory B10 cells. Blood, 117(2), 530-541. doi:10.1182/blood-2010-07-294249

4. Furuzawa-Carballeda, J., Hernández-Molina, G., Lima, G., Rivera-Vicencio, Y., Férez-Blando, K., \& Llorente, L. (2013). Peripheral regulatory cells immunophenotyping in Primary Sjögren's Syndrome: a cross-sectional study. Arthritis Research \& Therapy, 15(3), R68. doi:10.1186/ar4245

5. Daien, C. I., Gailhac, S., Mura, T., Audo, R., Combe, B., Hahne, M., \& Morel, J. (2014). Regulatory B10 Cells Are Decreased in Patients with Rheumatoid Arthritis and Are Inversely Correlated with Disease Activity. Arthritis \& Rheumatology, 66(8), 2037-2046. doi:10.1002/art.38666

6. Palomares O, Martin-Fontecha M, Lauener R, Traidl-Hoffmann C, Cavkaytar O, Akdis M, et al. Regulatory T cells and immune regulation of allergic diseases: roles of IL-10 and TGF-beta. Genes Immun 2014;15:511-20.

7. Akdis M, Burgler S, Crameri R, Eiwegger T, Fujita H, Gomez E, et al. Interleu- kins, from 1 to 37, and interferon-gamma: receptors, functions, and roles in dis- eases. J Allergy Clin Immunol 2011;127:701-21, e1-70.

8. Mauri, C., \& Menon, M. (2017). Human regulatory B cells in health and disease: therapeutic potential. Journal of Clinical Investigation, 127(3), 772-779. doi:10.1172/jci85113

9. Willis, T. (1672). De anima brutorum quae hominis vitalis ac sentitiva est: exercitationes duae. Londini: Typis E.F. impensis Ric. Davis, Oxon, 1672, 404-406.

10. Wilks, S. (1877). On cerebritis, hysteria and bulbar paralysis, as illustrative of arrest of function of the cerebrospinal centres. Guy's Hospital Reports, 22, 7-55.

11. Hughes, T. (2005). The early history of myasthenia gravis. Neuromuscular Disorders, 15(12), 878-886. https://doi.org/10.1016/j.nmd.2005.08.007

12. Pearce, J. (2004). Mary Broadfoot Walker (1888-1974): A historic discovery in myasthenia gravis. European Neurology, 53(1), 51-53. https://doi.org/10.1159/000084268

13. Weigert, C. (1901). Pathologisch-anatomischer Beitrag zur Erb'schen Krankheit [Myasthenia gravis]. Leipzig, Neurologisches Centralblatt, 20, 597-601.

14. Walker, M. (1934). Treatment of myasthenia gravis with physostigmine. The Lancet, 223(5779), 1200-1201. https://doi.org/10.1016/s0140-6736(00)94294-6 
15. Simpson, J. A. (1960). Myasthenia gravis: A new hypothesis. Scottish Medical Journal, 5(10), 419-436. https://doi.org/10.1177/003693306000501001

16. Osserman, K. E., Genkins, G. (1971). Studies in myasthenia gravis: Review of a twenty-year experience in over 1,200 patients. Mount Sinai Journal of Medicine, $38(6), 497-537$.

17. Katz, S. I., Parker, D., \& Turk, J. L. (1974). B-cell suppression of delayed hypersensitivity reactions. Nature, 251(5475), 550-551. doi:10.1038/251550a0

18. Neta, R., \& Salvin, S. B. (1974). Specific suppression of delayed hypersensitivity: the possible presence of a suppressor B cell in the regulation of delayed hypersensitivity. The Journal of Immunology, 113(6), 1716-25.

19. Wolf, S. D., Dittel, B. N., Hardardottir, F., \& Janeway, C. A. (1996). Experimental Autoimmune Encephalomyelitis Induction in Genetically B Cell-deficient Mice. Journal of Experimental Medicine, 184(6), 2271-2278. doi:10.1084/jem.184.6.2271

20. Mizoguchi, A., Mizoguchi, E., Smith, R. N., Preffer, F. I., \& Bhan, A. K. (1997). Suppressive Role of B Cells in Chronic Colitis of T Cell Receptor $\alpha$ Mutant Mice. The Journal of Experimental Medicine, 186(10), 1749-1756. doi:10.1084/jem.186.10.1749

21. Mizoguchi, E., Mizoguchi, A., Preffer, F. I., \& Bhan, A. K. (2000). Regulatory role of mature B cells in a murine model of inflammatory bowel disease. International Immunology, 12(5), 597-605. doi:10.1093/intimm/12.5.597

22. Evans, J. G., Chavez-Rueda, K. A., Eddaoudi, A., Meyer-Bahlburg, A., Rawlings, D. J., Ehrenstein, M. R., \& Mauri, C. (2007). Novel Suppressive Function of Transitional 2 B Cells in Experimental Arthritis. The Journal of Immunology, 178(12), 7868-7878. doi:10.4049/jimmunol.178.12.7868

23. Kalampokis, I., Yoshizaki, A., \& Tedder, T. F. (2013). IL-10-producing regulatory B cells (B10 cells) in autoimmune disease. Arthritis Research \& Therapy, 15(Suppl 1), S1. doi:10.1186/ar3907

24. Sheng, J. R., Quan, S., \& Soliven, B. (2014). CD1dhiCD5+B Cells Expanded by GMCSF In Vivo Suppress Experimental Autoimmune Myasthenia Gravis. The Journal of Immunology, 193(6), 2669-2677. doi:10.4049/jimmunol.1303397

25. Watanabe, R., Ishiura, N., Nakashima, H., Kuwano, Y., Okochi, H., Tamaki, K., ... Fujimoto, M. (2010). Regulatory B Cells (B10 Cells) Have a Suppressive Role in 
Murine Lupus: CD19 and B10 Cell Deficiency Exacerbates Systemic Autoimmunity. The Journal of Immunology, 184(9), 4801-4809. doi:10.4049/jimmunol.0902385

26. Yanaba, K., Bouaziz, J., Haas, K. M., Poe, J. C., Fujimoto, M., \& Tedder, T. F. (2008). A Regulatory B Cell Subset with a Unique CD1dhiCD5+ Phenotype Controls T Cell-Dependent Inflammatory Responses. Immunity, 28(5), 639-650. doi:10.1016/j.immuni.2008.03.017

27. Yanaba, K., Yoshizaki, A., Asano, Y., Kadono, T., Tedder, T. F., \& Sato, S. (2011). IL-10-Producing Regulatory B10 Cells Inhibit Intestinal Injury in a Mouse Model. The American Journal of Pathology, 178(2), 735-743.

doi:10.1016/j.ajpath.2010.10.022

28. Yang, M., Deng, J., Liu, Y., Ko, K., Wang, X., Jiao, Z., ... Lu, L. (2012). IL-10Producing Regulatory B10 Cells Ameliorate Collagen-Induced Arthritis via Suppressing Th17 Cell Generation. The American Journal of Pathology, 180(6), 2375-2385. doi:10.1016/j.ajpath.2012.03.010

29. Matsumoto, M., Baba, A., Yokota, T., Nishikawa, H., Ohkawa, Y., Kayama, H., ... Baba, Y. (2014). Interleukin-10-Producing Plasmablasts Exert Regulatory Function in Autoimmune Inflammation. Immunity, 41(6), 1040-1051. doi:10.1016/j.immuni.2014.10.016

30. Blair, P. A., Noreña, L. Y., Flores-Borja, F., Rawlings, D. J., Isenberg, D. A., Ehrenstein, M. R., \& Mauri, C. (2010). CD19+CD24hiCD38hi B Cells Exhibit Regulatory Capacity in Healthy Individuals but Are Functionally Impaired in Systemic Lupus Erythematosus Patients. Immunity, 32(1), 129-140. doi:10.1016/j.immuni.2009.11.009

31. Das, A., Ellis, G., Pallant, C., Lopes, A. R., Khanna, P., Peppa, D., ... Maini, M. K. (2012). IL-10-Producing Regulatory B Cells in the Pathogenesis of Chronic Hepatitis B Virus Infection. The Journal of Immunology, 189(8), 3925-3935. doi:10.4049/jimmunol.1103139

32. Van de Veen, W., Stanic, B., Yaman, G., Wawrzyniak, M., Söllner, S., Akdis, D. G., ... Akdis, M. (2013). IgG4 production is confined to human IL-10-producing regulatory B cells that suppress antigen-specific immune responses. Journal of Allergy and Clinical Immunology, 131(4), 1204-1212. doi:10.1016/j.jaci.2013.01.014

33. Karim, M. R., Zhang, H., Yuan, J., Sun, Q., \& Wang, Y. (2017). Regulatory B Cells in Seropositive Myasthenia Gravis versus Healthy Controls. Frontiers in Neurology, 8. doi:10.3389/fneur.2017.00043 
34. Karim, M. R., \& Wang, Y. F. (2019). Phenotypic identification of $\mathrm{CD} 19^{+} \mathrm{CD}^{+} \mathrm{CD} 1 \mathrm{~d}^{+}$regulatory B cells that produce interleukin 10 and transforming growth factor $\beta_{1}$ in human peripheral blood. Archives of Medical Science, 15(5), 1176-1183. doi:10.5114/aoms.2018.77772

35. Matsushita, T., Horikawa, M., Iwata, Y., \& Tedder, T. F. (2010). Regulatory B Cells (B10 Cells) and Regulatory T Cells Have Independent Roles in Controlling Experimental Autoimmune Encephalomyelitis Initiation and Late-Phase Immunopathogenesis. The Journal of Immunology, 185(4), 2240-2252. doi:10.4049/jimmunol.1001307

36. Jayam Trouth, A., Dabi, A., Solieman, N., Kurukumbi, M., \& Kalyanam, J. (2012). Myasthenia gravis: A review. Autoimmune Diseases, 2012, 1-10. https://doi.org/10.1155/2012/874680

37. Saruhan-Direskeneli, G., \& Sawalha, A. H. (2019). Autoimmune myasthenia gravis. Genetics of Rare Autoimmune Diseases, 203-219. https://doi.org/10.1007/978-3-03003934-9_11

38. Pourmand, R. (1997). Myasthenia gravis. Disease-a-Month, 43(2), 70-109. https://doi.org/10.1016/s0011-5029(97)90033-x

39. Karim, M. R., \& Wang, Y. F. (2016). The study progress of B cells and Neuroimmunological diseases. Journal of Neurology \& Neurophysiology, 07(02). https://doi.org/10.4172/2155-9562.1000369

40. Yilmaz, V., Maillard, S., Truffault, F., Bolgert, F., Behin, A., Regnard, J., BerrihAknin, S., \& Le Panse, R. (2018). Regulatory B cells in myasthenia gravis are differentially affected by therapies. Annals of Clinical and Translational Neurology, 5(11), 1408-1414. https://doi.org/10.1002/acn3.645

41. Sun, F., Ladha, S. S., Yang, L., Liu, Q., Shi, S. X., Su, N., Bomprezzi, R., \& Shi, F. (2014). Interleukin-10 producing-B cells and their association with responsiveness to rituximab in myasthenia gravis. Muscle \& Nerve, 49(4), 487-494. https://doi.org/10.1002/mus.23951

42. Sheng, J. R., Rezania, K., \& Soliven, B. (2016). Impaired regulatory B cells in myasthenia gravis. Journal of Neuroimmunology, 297, 38-45. https://doi.org/10.1016/j.jneuroim.2016.05.004

43. Guptill, J. T., Yi, J. S., Sanders, D. B., Guidon, A. C., Juel, V. C., Massey, J. M., Howard, J. F., Scuderi, F., Bartoccioni, E., Evoli, A., \& Weinhold, K. J. (2015). Characterization of B cells in muscle-specific kinase antibody myasthenia gravis. 
Neurology - Neuroimmunology Neuroinflammation, 2(2), e77. https://doi.org/10.1212/nxi.0000000000000077

44. Okur, F. V., \& Brenner, M. K. (2010). Cellular immunotherapy of cancer. Methods in Molecular Biology, 319-345. https://doi.org/10.1007/978-1-60761-786-0_19

45. Egwuagu, C. E., \& Yu, C. (2015). Interleukin 35-Producing B cells (i35-breg): A new mediator of regulatory B-cell functions in CNS autoimmune diseases. Critical Reviews in Immunology, 35(1), 49-57. https://doi.org/10.1615/critrevimmunol.2015012558

46. Gallego-Valle, J., Pérez-Fernández, V., Correa-Rocha, R., \& Pion, M. (2018). Generation of human breg-like phenotype with regulatory function in vitro with bacteria-derived Oligodeoxynucleotides. International Journal of Molecular Sciences, 19(6), 1737. https://doi.org/10.3390/ijms19061737

47. Knippenberg, S., Peelen, E., Smolders, J., Thewissen, M., Menheere, P., Cohen Tervaert, J. W., Hupperts, R., \& Damoiseaux, J. (2011). Reduction in IL-10 producing B cells (Breg) in multiple sclerosis is accompanied by a reduced naive/memory Breg ratio during a relapse but not in remission. Journal of Neuroimmunology, 239(1-2), 80-86. https://doi.org/10.1016/j.jneuroim.2011.08.019

48. Quan, C., Yu, H., Qiao, J., Xiao, B., Zhao, G., Wu, Z., Li, Z., \& Lu, C. (2012). Impaired regulatory function and enhanced intrathecal activation of B cells in neuromyelitis optica: Distinct from multiple sclerosis. Multiple Sclerosis Journal, 19(3), 289-298. https://doi.org/10.1177/1352458512454771

49. Han, J., Sun, L., Fan, X., Wang, Z., Cheng, Y., Zhu, J., \& Jin, T. (2016). Role of regulatory B cells in neuroimmunologic disorders. Journal of Neuroscience Research, 94(8), 693-701. https://doi.org/10.1002/jnr.23749

50. Menon, M., Blair, P. A., Isenberg, D. A., \& Mauri, C. (2016). A regulatory feedback between Plasmacytoid dendritic cells and regulatory B cells is aberrant in systemic lupus Erythematosus. Immunity, 44(3), 683-

697. https://doi.org/10.1016/j.immuni.2016.02.012

51. Yang, M., Sun, L., Wang, S., Ko, K., Xu, H., Zheng, B., Cao, X., \& Lu, L. (2010). Cutting edge: Novel function of B cell-activating factor in the induction of IL-10producing regulatory B cells. The Journal of Immunology, 184(7), 33213325. https://doi.org/10.4049/jimmunol.0902551

52. Genestier, L., Taillardet, M., Mondiere, P., Gheit, H., Bella, C., \& Defrance, T. (2007). TLR agonists selectively promote terminal plasma cell differentiation of $B$ 
cell subsets specialized in thymus-independent responses. The Journal of Immunology, 178(12), 7779-7786. https://doi.org/10.4049/jimmunol.178.12.7779

53. Grammer, A. C., \& Lipsky, P. E. (2002). CD154-CD40 interactions mediate differentiation to plasma cells in healthy individuals and persons with systemic lupus erythematosus. Arthritis \& Rheumatism, 46(6), 14171429. https://doi.org/10.1002/art.10287

54. Aguiar, R., Araújo, C., Martins-Coelho, G., \& Isenberg, D. (2017). Use of Rituximab in systemic lupus Erythematosus: A single center experience over 14 years. Arthritis Care \& Research, 69(2), 257-262. https://doi.org/10.1002/acr.22921

55. Iwata, Y., Matsushita, T., Horikawa, M., DiLillo, D. J., Yanaba, K., Venturi, G. M., Szabolcs, P. M., Bernstein, S. H., Magro, C. M., Williams, A. D., Hall, R. P., St Clair, E. W., \& Tedder, T. F. (2011). Characterization of a rare IL-10-competent Bcell subset in humans that parallels mouse regulatory B10 cells. Blood, 117(2), 530541. https://doi.org/10.1182/blood-2010-07-294249

56. Maseda, D., Smith, S. H., DiLillo, D. J., Bryant, J. M., Candando, K. M., Weaver, C. T., \& Tedder, T. F. (2011). Regulatory B10 cells differentiate into antibody-secreting cells after transient IL-10 production in vivo. The Journal of Immunology, 188(3), 1036-1048. https://doi.org/10.4049/jimmunol.1102500

57. Floudas, A., Amu, S., \& Fallon, P. G. (2016). New insights into IL-10 dependent and IL-10 independent mechanisms of regulatory B cell immune suppression. Journal of Clinical Immunology, 36(S1), 25-33. https://doi.org/10.1007/s10875-016-0263-8 


\section{FIGURES:}

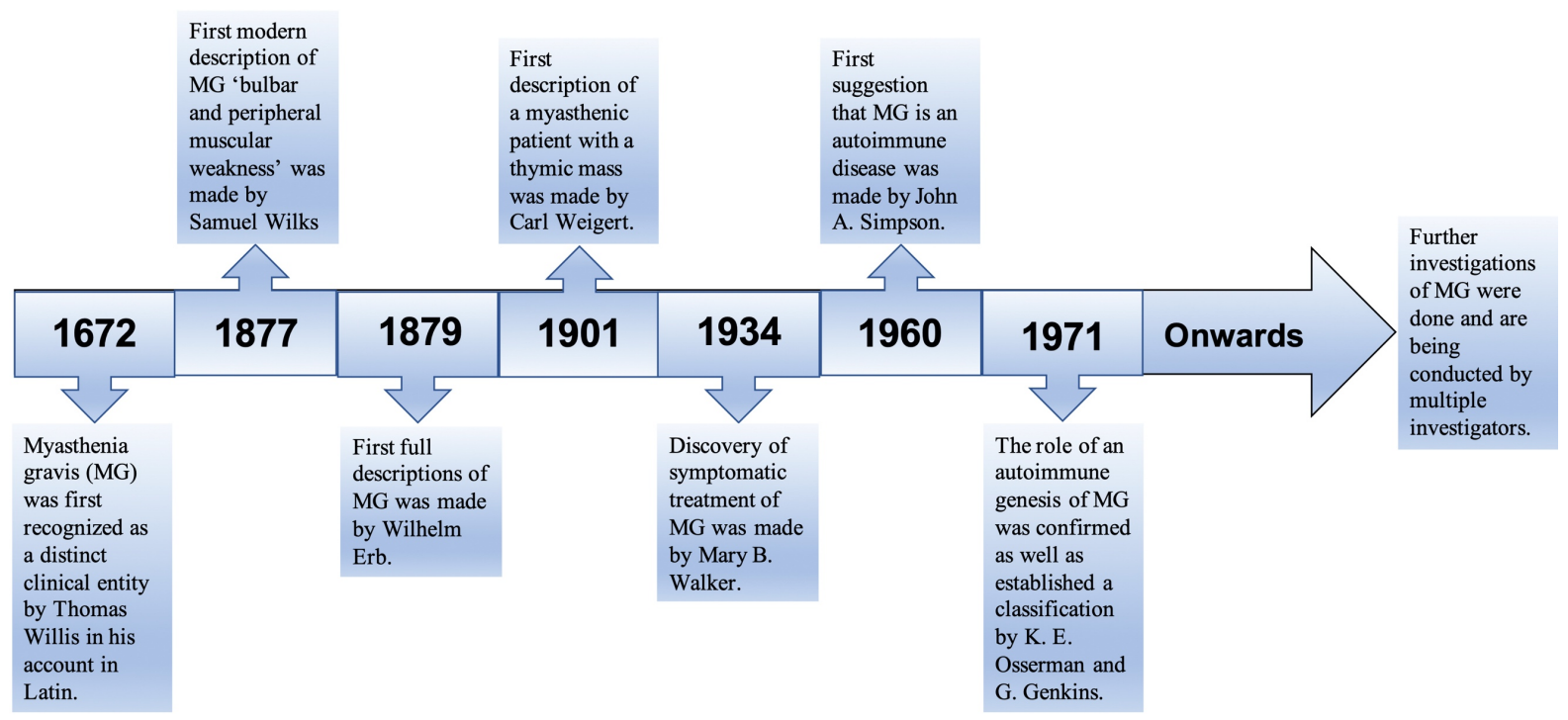

Figure 1: A timeline of the history of myasthenia gravis.

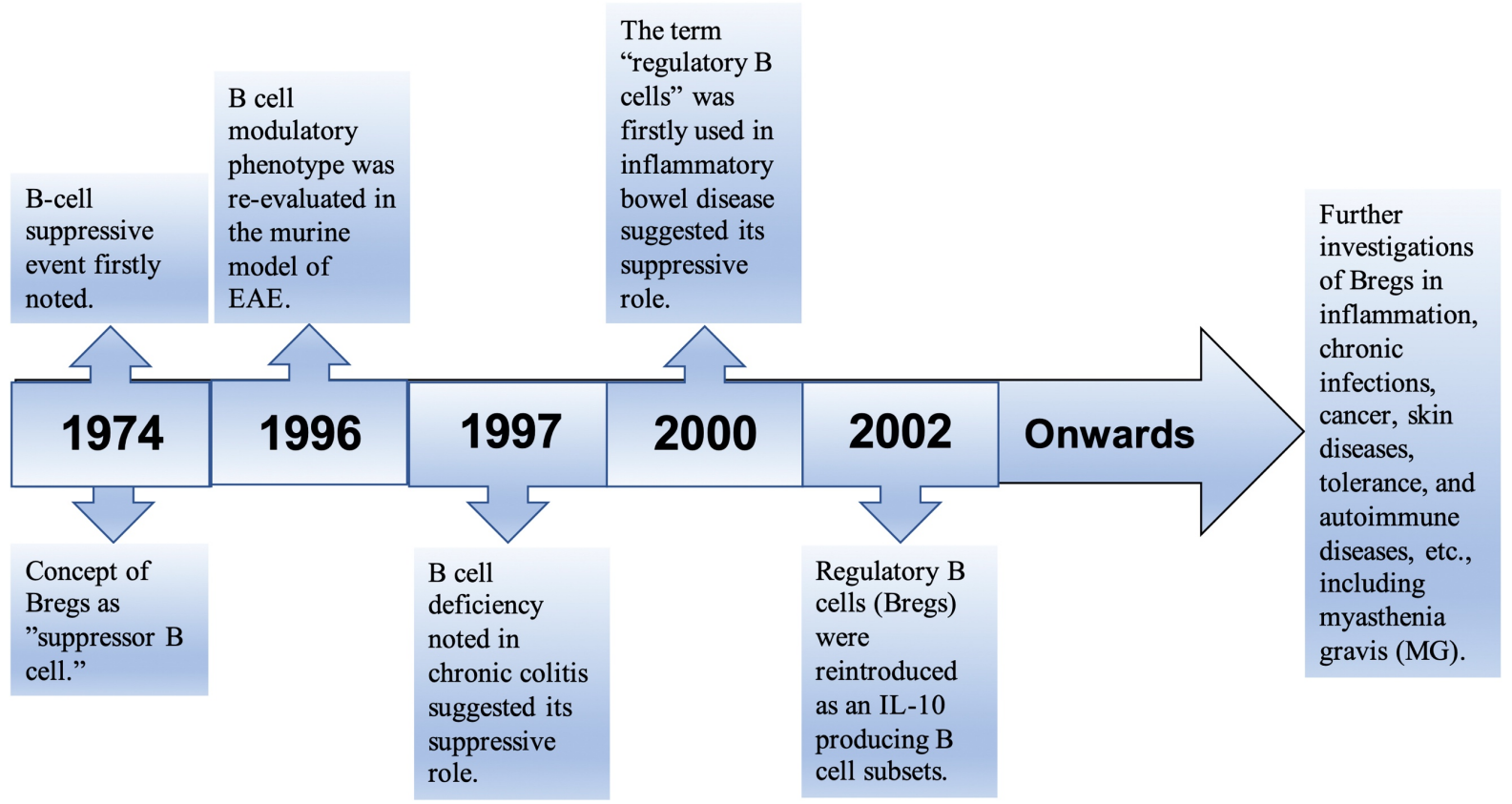

Figure 2: A timeline of the history of regulatory $B$ cells. 


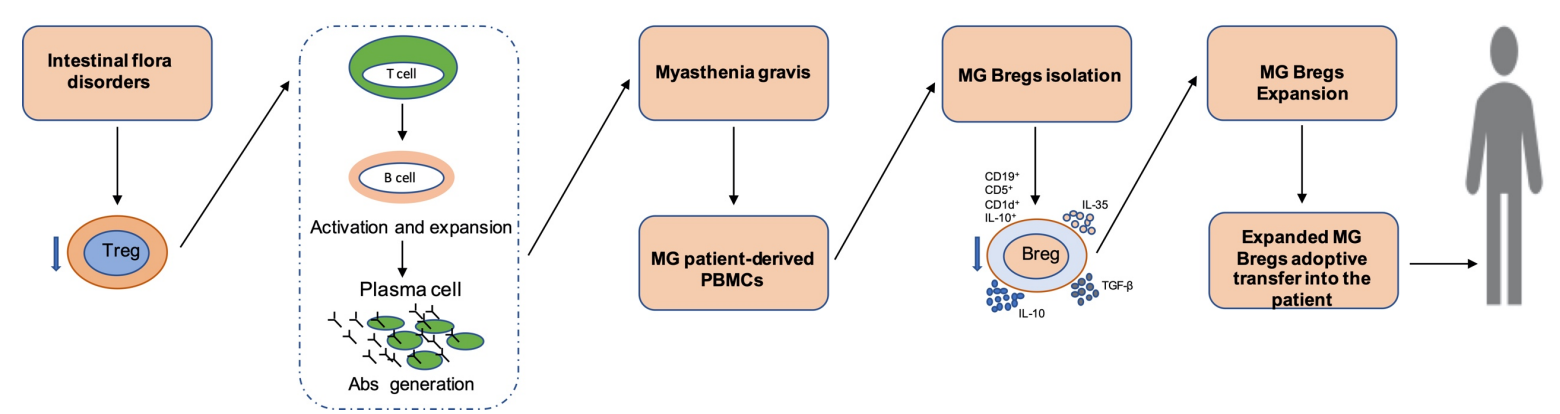

Figure 3: Expansion and adoptive transfer of regulatory $B$ cells of myasthenia gravis. 